\title{
Using concept mapping principles in PowerPoint
}

\author{
I. M. Kinchin and L. B. Cabot \\ James Clerk Maxwell Building, Kings College London, London, UK
}

\begin{abstract}
The use of linear PowerPoint templates to support lectures may inadvertently encourage dental students to adopt a passive approach to learning and a narrow appreciation of the field of study. Such presentations may support short-term learning gains and validate assessment regimes that promote surface learning approaches at the expense of developing a wider appreciation of the field that is necessary for development of clinical expertise. Exploitation of concept mapping principles can provide a balance for the negative learning behaviour that is promoted by the unreflective use of PowerPoint. This increases the opportunities for students to access holistic knowledge structures that are indicators of expertise. We illustrate this using the example of partial denture design and show that undergraduates' grasp of learning and teaching issues is suffi-
\end{abstract}

ciently sophisticated for them to appreciate the implications of varying the mode of presentation. Our findings indicate that students understand the strategic value of bullet-pointed presentations for short-term assessment goals and the benefits of deep learning mediated by concept mapping that may support longer term professional development. Students are aware of the tension between these competing agendas.

Key words: concept map; PowerPoint; affordances for learning.

(C) 2007 The Authors. Journal Compilation (c) 2007 Blackwell Munksgaard

Accepted for publication, 27 February 2007

\section{Introduction}

$\mathrm{T}$ HE FORMAL LECTURE is still a dominant teaching format within dental education and higher education in general. However, change is taking place. The teaching environment is being modernised and digital technology has been introduced providing opportunities for multimedia presentations. Lectures and presentations are now regularly supported with PowerPoint. Whilst PowerPoint offers a mechanism to use text and graphics to illustrate a lecture, the software is not without its critics. One of the most forceful critics of PowerPoint has been Edward Tufte (1). In his essay, Tufte criticises several interrelated aspects of PowerPoint with a focus on pedagogical consequences. These include an over reliance on bullet points, the inappropriate use of templates and the linearity imposed by slides sequences that do not link with students' prior understanding. In addition, PowerPoint slides have been shown to be a poor medium to deliver large amounts of textual information. This last point is linked to the role of the handout and has been discussed in detail elsewhere (2).

In Tufte's (1) consideration of the 'pedagogy of PowerPoint', he seems to miss the point that PowerPoint is a tool to facilitate pedagogy and not drive it. But for this to happen, the lecturer needs to have considered pedagogical issues before starting to construct the supporting PowerPoint presentation. In this article we are aiming to support colleagues in their use of PowerPoint to maximise the educational gains that this powerful tool has to offer. To do this, colleagues need to consider how PowerPoint can be used to promote the transformation of information that is needed to encourage meaningful learning of the material that is presented to students (3). We acknowledge that there are numerous factors that influence the success of a lecture (such as the content and the style of the teacher's delivery), but as PowerPoint is such a common feature of university lectures, it offers a gateway into discussions about teaching that will resonate with many practitioners in higher education. One of the issues with which many practitioners will be familiar is the apparent induction of student passivity that results from the use of PowerPoint. Such behaviour is described below in terms of affordances for learning.

\section{Affordances for learning}

The source of the term 'affordance' is grounded in environmental psychology and was coined by Gibson $(4,5)$. It is now finding its way into the education 
literature to describe learning opportunities for students within information and communications technology (ICT)-rich learning environments (e.g. 6-8) and provides a framework here for the consideration of the effectiveness of the presentation of teaching materials. Central to affordance theory is that the relationship between the perceiver (human) and the perceived (environment) constructs the possibility for certain behaviour. Within the learning environment that is typically found within higher education, affordances are provided by interactions between the software (PowerPoint), the teachers and the students. These affordances are seen to support certain types of teaching/learning actions and encourage specific types of behaviour by the teachers and by their students. The key affordances for learning that are promoted by PowerPoint and by concept mapping are summarised in Table 1.

The concept map is a product of 25 years of research and development, focusing on helping students learn how to learn $(9,10)$. Concept mapping builds on Ausubel's assimilation theory of meaningful learning (11) and fits well with constructivist learning perspectives (12) Concept maps are constructed explicitly to illustrate the links between ideas and to highlight multiple ways of connecting concepts within a developing expert-knowledge framework, and have been found to offer utility in the higher education arena in both promoting and assessing conceptual change (e.g. $13,14)$. In contrast, PowerPoint is seen largely as a tool to deliver content (15) and as such can be seen as being supportive of an objectivist/positivist view of teaching in which transmission of knowledge is seen as the key aim. Typically, PowerPoint presentations tend to overemphasise a linear structure of knowledge to the exclusion of alternative perspectives, as a continuous authoritative voice that presents the definitive account. The linear nature of templates supplied with PowerPoint drives teachers down a highly sequential teaching pathway. Such an approach to teaching is associated with a rote learning approach by students.

TABLE 1. Comparing the affordances for learning offered by PowerPoint and by concept mapping

\begin{tabular}{ll}
\hline PowerPoint & Concept mapping \\
\hline $\begin{array}{l}\text { Promotes single } \\
\text { perspective }\end{array}$ & Promotes multiple perspectives \\
Promotes linear & Promotes integrated knowledge \\
knowledge structure & structure \\
Reflects objectivist & Reflects constructivist \\
epistemology & epistemology \\
Focus on content & Focus on learning \\
Assessment-led & Understanding-led \\
Promotes passivity & Promotes dialogue \\
Promotes rote learning & Promotes meaningful learning \\
\hline
\end{tabular}

This has been described as the 'pedagogy of PowerPoint' by Tufte (1), who, as we have seen, considers the software as having a negative impact on the quality of teaching and learning in higher education.

It is this tension between concept mapping and PowerPoint that can be exploited by teachers to reveal and reflect upon students' multiple perspectives of the subject being taught, with the dual aim of improving the learning experience for students and developing reflective practice among teachers by encouraging them to think beyond the linear sequence. The tendency for computer-based materials to follow a linear, assembly line mode has been commented upon by Conole and Dyke (16). Whilst Webb (17) has commented that, 'ICT-rich environments already provide a range of affordances that have been shown to enable learning of science but integrating these affordances with other pedagogical innovations provides even greater potential for enhancement of students' learning'. The complementary affordances for learning created by PowerPoint and concept mapping are likely candidates to support such enhancement.

\section{An example: the design of removable partial dentures}

Undergraduate dental education has the aim of producing a dentist who is capable of undertaking a wide variety of tasks in a safe and competent manner. Crucial to the development of such a person is the idea that clinical practice must have a sound theoretical underpinning. PowerPoint is used extensively in the development of that underpinning. The example chosen to illustrate the concept mapping/PowerPoint debate is the design of removable partial dentures (RPD). We describe a way of improving the learning behaviours afforded by the teaching materials presented to students.

Many integrated teaching strategies are usually employed in the teaching of RPD design, including clinical/technical demonstrations and practical exercises supported by tutorials and lectures. That said, the design stages are often presented and/or reinforced in a linear, bullet-pointed, manner within PowerPoint as outlined in Fig. 1. The concept of RPD design is however pictorial and lends itself well to the principles of concept mapping.

What the undergraduate does not necessarily appreciate is the fact that the design stages are just parts of the whole. To take this linear design path meaningfully, he/she must have a vision of the end product; that is, a workable design. Passing through the defined 


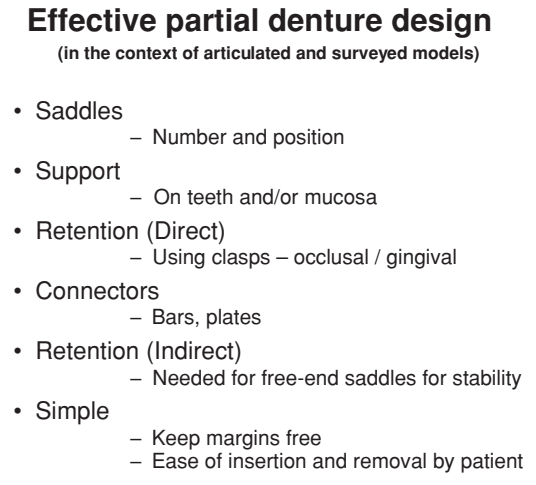

Fig. 1. Introductory PowerPoint slide for a lecture on 'Effective partial denture design'. This slide utilises one of the style templates available with PowerPoint, resulting in a list of six bullet points.

design stages in no way gives the undergraduate any idea of how the defined variables interrelate, the relative importance of those variables, or whether the end product is appropriate for a particular set of circumstances. Nor, if there are significant flaws in the design produced by an undergraduate, does it give the clinical teacher an insight into the undergraduates' understanding of the process that led to flawed design.

If the clinical teacher is aware of the undergraduate's developing conceptual model of the design process (Figs 2, 3 present concept maps of such models), potentially his/her task becomes much easier. It is more than likely that most will consider the content of these concept maps to be flawed, but the point is the teacher is able to compare these models with his/her own. If the conceptual overlap between student's map and teacher's map is significant, clinical practice can move forward in the knowledge that theoretical underpinning is secure. If it is not, the teacher knows that $\mathrm{s} /$ he must revisit and reinforce aspects of theory. Critically, the teaching of partial denture design can now become a predictable process, particularly if one recognises the possible cognitive conflict that may exist between chains of practice employed in clinical reasoning of the novice practitioner (18) with the more holistic knowledge structures that might be expected of an expert in the field (19). Being able to recognise the significance of these different knowledge structures is important if they are to gain the maximum benefit from their teaching in both the clinical and academic contexts.

\section{Methods for gaining students' perspectives on affordances}

It is important that the theoretical application of affordance theory described here can be translated into student behaviours if this work is to have ecological validity. To establish this, a cohort of third year undergraduate KCL dental students ( $n=37$ - present on a clinical teaching day) who had recently completed their introductory programme in RPD design were asked to complete a questionnaire (see Appendix) to gauge their perceptions of the two PowerPoint slides shown in Figs 1, 2. These students had not previously been given information in the concept mapping format. This questionnaire has been piloted in other academic disciplines by one of the authors (I.K.) to determine its reliability and validity.

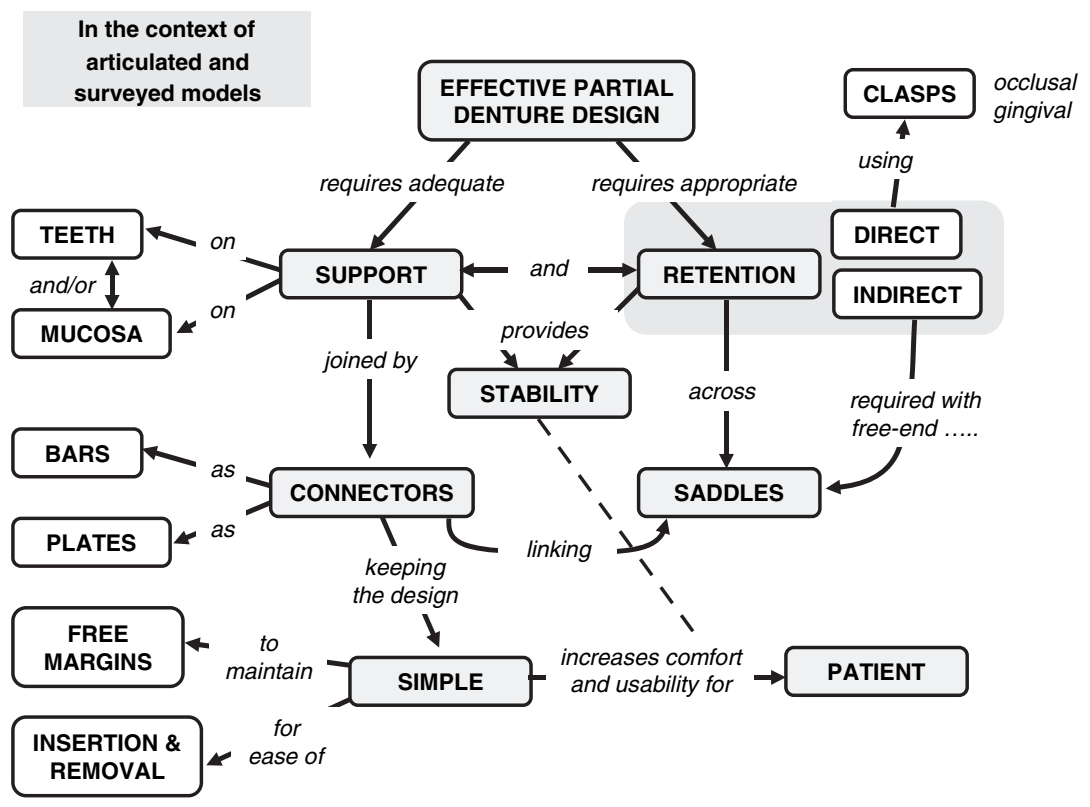

Fig. 2. Introductory PowerPoint slide on 'Effective partial denture design'. The content on this slide is arranged as a concept map that emphasises the links between the main elements. 
Fig. 3. A concept map of 'effective partial denture design' from the perspective of a patient whose chief concerns are related to the effectiveness of the denture (function) and its appearance (aesthetics). The map shows how these key concerns are related to aspects of the design process.

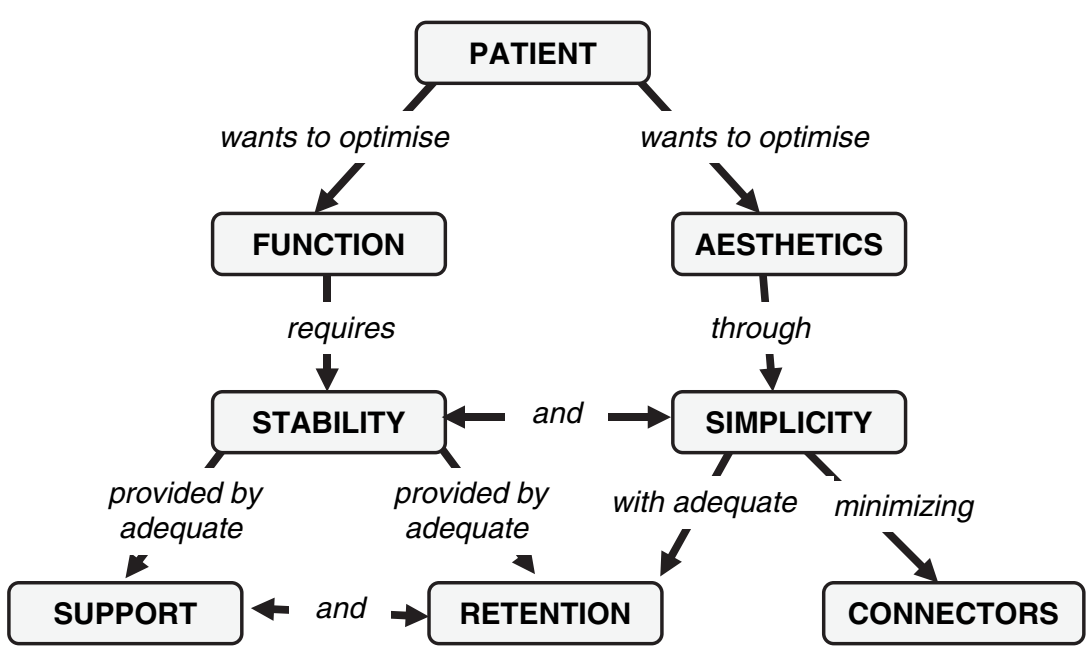

Its consideration within dentistry is offered here for the first time. After completion of the questionnaires, students were engaged in focus group discussions about their responses (in groups of six to nine students). Responses to the questionnaire were used to guide the discussion. These discussions were not taped, but students were asked to make notes on their questionnaires of key issues raised.

We have noted that the teaching of RPD design is multifaceted; the concern with this study was simply the value to the student of presenting the sequential approach to design in bullet-pointed PowerPoint format in student learning.

\section{Results}

When asked whether the slides helped them to memorise key points, $92 \%$ of the students in our sample felt that the bullet-point format helped memorisation (compared with $43 \%$ for the concept map format). This pattern of responses is linked to a subsequent question in which $73 \%$ of respondents thought that the bullet-point format helped to learn the material quickly (compared with $43 \%$ for the concept mapping format). In discussions with the students that followed the questionnaire, the need to memorise information quickly was seen to be important for their preparation for examinations which they saw as different from (and possibly in conflict with) learning for understanding. This raises a number of questions about the nature of the assessment regime. In this instance, it seems to be acting as an impediment to the development of understanding as the students regard the examinations to be divorced from developing expertise in the subject.
When asked whether the slides helped the students to understand the connections between the major ideas presented, 95\% agreed that the concept map format helped whilst only $16 \%$ felt that the bulletpoint format helped in this way. The students expressed the view that expert understanding (in which links between ideas were explicit and understood) was important for their future professional development, but was not required for the more immediate demands of passing examinations.

\section{Discussion}

The suggestion from this small sample is that students react to the affordances offered by PowerPoint and by concept mapping in predictable ways (as indicated in Table 1). If clinical teachers understand such student behaviours, it will help them to manipulate their teaching materials to maximise the level of student engagement with the subject.

The view promoted within Fig. 2 may be criticised for placing the patient at the bottom of the hierarchy of ideas, suggesting relative unimportance. This positioning may be understandable when the focus is on the partial denture and its design where patient satisfaction is seen as an end point for all the other steps in the process. However, concept mapping is a tool that invites alternative perspectives (20). An equally valid perspective to that shown in Fig. 2 would be that which focuses on the patient (Fig. 3). Within this undergraduate map the hierarchy of ideas may be partially reversed as 'support' and 'retention' are seen as a means to an end that underpin the patient's immediate concerns for 'function' and 'aesthetics'. Appreciation of this perspective may help the dentist to explain to the patient some of the design 
decisions that have to be made to produce a satisfactory denture. We suggest that the alternative perspective develops a deeper understanding of RPD design and has the potential to enhance practitioner design skills.

If, as stated by Caine and Caine (21), 'the fundamental task of the teacher is to facilitate the selforganization of the student', then the teacher needs to be aware of the multiplicity of starting points that can exist within a cohort of students. Such awareness may be supported by examining the possible structural variation of concept maps that may be produced to portray material to be taught. This puts teachers in the position of 'active innovators' in their own teaching. Appreciation of these multiple perspectives may also help the teacher to consider his/her teaching strategy in relation to his/her own learning strategy and reflect upon ways to compensate for bias in any given direction $(22,23)$. PowerPoint slides are often presented as handouts, or placed on the web for reference. However, Chemero (24) agued that affordances are features of a whole situation. Therefore, as the situation changes (from lecture to private study), so do the affordances offered by the presentation. In the absence of the lecturer's narrative, the learning value of PowerPoint slides, be they bullet-point or concept map, is questionable.

The structure and mode of presentation of information given to undergraduate dental students may impact significantly upon their approach to learning. The typical presentation style promoted by the use of PowerPoint templates encourages the projection of linear knowledge structures which, although contextually appropriate for the clinical environment, may promote a passive or surface approach to learning. Incorporation of concept mapping principles when designing PowerPoint presentations may promote a more active/deep approach to study that helps the student to appreciate a more holistic view of the discipline in which the linear chains of clinical reasoning are embedded.

Effective teaching materials should help the students to appreciate the learning behaviours that are expected (e.g. memorisation or active engagement). We have shown that students are able to perceive the affordances for learning that are promoted by various teaching approaches and presentation styles. However, their adoption of matching learning approaches is tempered by their perceptions of what is required to succeed within the current assessment regime.

We must be careful about driving our dental students down a particular pedagogical path and thereby limiting their learning options, the networks of understanding they are able to make and, consequentially, their professional development. There are significant issues here for our understanding of student learning and developing appropriate assessment mechanisms. The strategies for learning and understanding a subject should be synonymous with those for preparing for their professional examinations. The fact that on occasions they are not, perhaps presents uncomfortable questions for those who design and prepare those assessment procedures.

\section{Conclusion}

Sequential PowerPoint presentations and concept mapping present very different pedagogical approaches to student learning. Students in this study were quite clear in their opinion that a bullet-pointed list is more useful than concept mapping if the aim is to memorise facts (i.e. a surface approach to learning). But they were just as clear that concept mapping is a more useful strategy if the aim is to make links between ideas and therefore gain a better understanding of the subject (i.e. a deep approach to learning). The way in which an undergraduate dental course requires students to oscillate between surface and deep approaches, and between a clinical (linear) focus and an academic (holistic) appreciation, may present extreme cognitive challenges for many students. Creating an awareness of this challenge is the first step if we are to help students navigate through it successfully.

\section{Recommendations}

We suggest that a combination of teaching approaches could have significant merit and introducing concept mapping early in the teaching of a particular subject or idea, frames the students' understanding in a particular way which perhaps fits into and compliments the sequential style of the bulleted PowerPoint approach. This sequence also needs to fit explicitly with the wider, underlying network of understanding. In this way the students' affordances can facilitate their historically favoured bulleted approach; a strategy they see as appropriate for examination success while developing a far deeper understanding of the subject that we argue is more important for success as a practising dentist and one that has a commitment to continuing professional development. 


\section{References}

1. Tufte ER. The cognitive style of PowerPoint. Cheshire, CT: Graphics Press LLC, 2003.

2. Kinchin IM. Developing PowerPoint handouts to support meaningful learning. Br J Educ Technol 2006: 37: 647-650.

3. Kinchin IM, Hay DB. The myth of the research-led teacher. Teachers Teaching: Theory Pract 2007: 13: 43-61.

4. Gibson JJ. The theory of affordances. In: Shaw R, Brandsford J, eds. Perceiving, acting and knowing: toward an ecological psychology. New York: LEA, 1977: 67-82.

5. Gibson JJ. The ecological approach to visual perception. Boston, MA: Houghton Mifflin, 1979.

6. Laurillard D, Stratfold M, Luckin R, Plowman L, Taylor J. Affordances for learning in a non-linear narrative medium. J Interact Media Educ 2000: 62: 1-19.

7. Kennewell S. Using affordances and constraints to evaluate the use of information and communications technology in teaching and learning. J Tech Teach Educ 2001: 10: 101-116.

8. Kozma R. The material features of multiple representations and their cognitive and social affordances for science understanding. Learn Instruct 2003: 13: 205-216.

9. Novak JD. Learning, creating and using knowledge: concept maps as facilitative tools in schools and corporations. Hillsdale, NJ: Lawrence Erlbaum Associates, 1998.

10. Novak JD, Caňas AJ. The theory underlying concept maps and how to construct them. Technical Report IHMC Cmap Tools 2006-1, Florida Institute for Human and Machine Cognition, 2006 Available online at: http://cmap.ihmc.us/Publications/ResearchPapers / TheoryUnderlyingConceptMaps.pdf. Accessed 18 June 2007.

11. Ausubel DP. The acquisition and retention of knowledge: a cognitive view. Dordrecht: Kluwer Academic Publishers, 2000.

12. Trowbridge JE, Wandersee JH. Theory-driven graphic organisers. In: Mintzes JJ, Wandersee JH, Novak JD, eds. Teaching science for understanding: a human constructivist view. San Diego, CA: Academic Press, 1998: 95-131.

13. Gravett SJ, Swart E. Concept mapping: a tool for promoting and assessing conceptual change. S Afr J High Educ 1997: 11: 122-126.
14. Daley BJ. Facilitating learning with adult students through concept mapping. J Cont High Educ 2002: 50: 21-31.

15. Szabo A, Hastings N. Using IT in the undergraduate classroom: should we replace the blackboard with PowerPoint? Comput Educ 2000: 35: 175-187.

16. Conole G, Dyke M. What are the affordances of information and communication technologies? ALT-J 2004: 12: 113-124.

17. Webb ME. Affordances of ICT in science learning: implications for an integrated pedagogy. Int J Sci Educ 2005: 27: 705-735.

18. de Cossart L, Fish, D. Cultivating a thinking surgeon: new perspectives on clinical teaching, learning and assessment. Harley: tfm Publishing, 2005.

19. Bradley JH, Paul R, Seeman E. Analyzing the structure of expert knowledge. Inform Mang 2006: 43: 77-91.

20. Kinchin IM, Alias M. Exploiting variations in concept map morphology as a lesson-planning tool for trainee teachers in higher education. J Serv Educ 2005: 31: 569591.

21. Caine RN, Caine G. Making connections: teaching and the human brain. Menlo Park, CA: Addison-Wesley Publishing Company, 1994.

22. Huai H. Cognitive style: its relations to memory capacity and concept mapping. Netherlands: Doctoral Dissertation, University of Twente, 2000.

23. Rayner S, Riding R. Towards a categorisation of cognitive styles and learning styles. Educ Psychol 1997: 17: 5-27.

24. Chemero A. An outline of a theory of affordances. Ecol Psychol 2003: 15: 181-195.
Address:
Dr Ian M. Kinchin
James Clerk Maxwell Building
Kings College London
57 Waterloo Road
London SE1 8 WA
UK
Tel: +44 (0)20 78483987
Fax: +44 (0)20 78483481
e-mail: ian.kinchin@kcl.ac.uk

\section{Appendix: questionnaire used to elicit student perspective}

Each of the following questions was presented for consideration alongside each of the two slides (Figs 1,2)

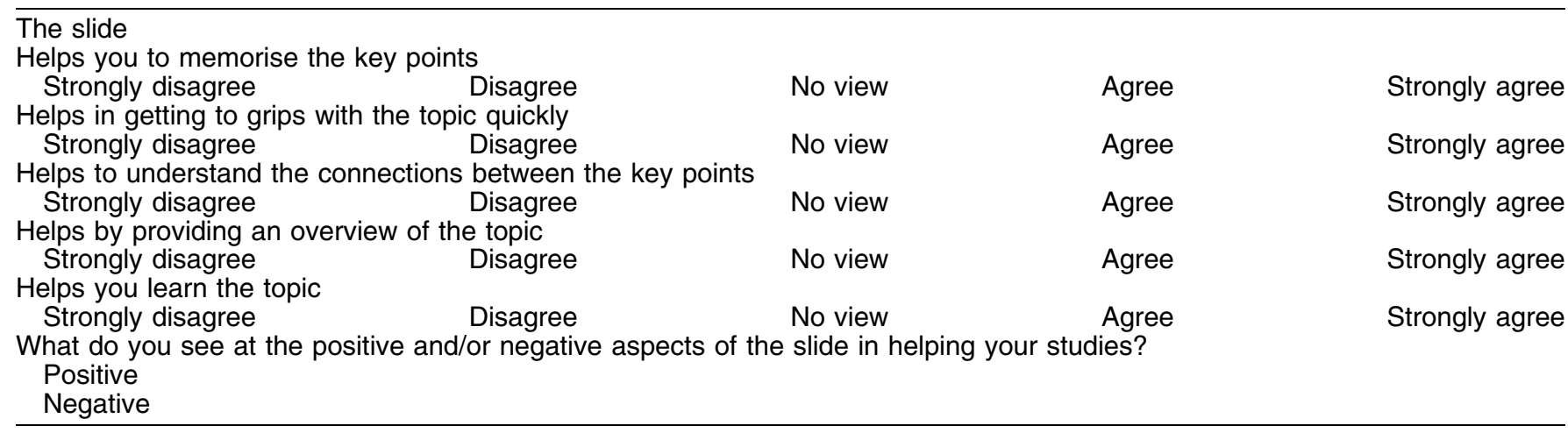

